\title{
Patoloji Eğitiminde Harmanlanmış Öğrenme Yaklaşımının Akademik Başarı ve Memnuniyet Üzerine Etkisi
}

\section{The effect of the blended learning approach in pathology education on academic achievement and satisfaction}

\author{
Arif Onan' (ORCID ID: 0000-0003-1666-9078) \\ Alp Usubütün² (ORCID ID: 0000-0001-9572-7875) \\ Barlş Sezerl' (ORCID ID: 0000-0003-0695-0819) \\ ${ }^{1}$ Hacettepe Üniversitesi T1P Fakültesi, Tıp Eğitimi ve Bilişimi AD \\ ${ }^{2}$ Hacettepe Üniversitesi T1P Fakültesi, Tıbbi Patoloji AD \\ Sorumlu Yazar: \\ Arif Onan \\ Hacettepe Üniversitesi T1P Fakültesi, Tıp Eğitimi ve Bilişimi AD Sıhhiye, Ankara \\ Tel: 03123052617 e-posta: aonan@hacettepe.edu.tr
}

Anahtar Sözcükler:

Patoloji eğitimi, Sanal ögrenme, Dijital patoloji

Keywords:

Pathology education,

Virtual Microscopy,

Blended learning, Digital pathology

Gönderilme Tarihi

Submitted:07.11.2018

Kabul Tarihi

Accepted: 15.03.2019 mikroskop, Harmanlanmış

ÖZET:

Amaç: Hacettepe Üniversitesi Tıp Fakültesinde patoloji eğitimi sistem temelli program içerisinde amfi dersi ve laboratuar uygulaması şeklinde gerçekleşmektedir. Entegre program yürüten tıp fakültelerinde patoloji öğretimi tıp öğrencilerinin üç temel alanda yetkinlik kazanmalarını amaçlamaktadır. Bunlar; a- Hastalık mekanizmalarının anlaşılması, bMekanizmaların organ sistem patolojisine entegrasyonu ve c- patolojinin tanısal tıbba uygulanmasıdır. Mevcut uygulama öğrencinin derse katılımı, mikroskop kullanma ve preperatları değerlendirebilmelerinde sorunlar içermektedir. Bu çalışma kapsamında patoloji öğretiminde öğrenme merkezli ve teknoloji destekli bir öğretim tasarımının etkisi araştırılmıştır.

Gereç ve Yöntem: Çalışma 2017-2018 akademik yılı 3. sınıf Ürogenital Sistem ders kurulunda 261 öğrenci ile gerçekleştirilmiştir. Tasarım aşağıdaki unsurları içermektedir: a- Patoloji ders içeriği sistematik ve elektronik indeksli kitap formatında hazırlanmıştır. b- Değerlendirme sorularına yer verilmiştir. cÖğrencilerin tartışacağı, geribildirim verebilecekleri elektronik iletişim kanalları oluşturulmuştur.

Makale Künyesi: Onan A, Usubütün A, Sezer B. Patoloji Eğitiminde Harmanlanmış Öğrenme Yaklaşımının Akademik Başarı ve Memnuniyet Üzerine Etkisi. Tip Eğitimi Dünyası. 2019;18(54): 76-87 
d- Öğrencinin elektronik preperat arşivi ve sanal mikroskop uygulamasına erişimi sağlanmıştır. e- Veri toplamada komite çoktan seçmeli sinav formu, patoloji laboratuar sinav formu, öğrenci program değerlendirme formu ve eğitici refleksiyon formundan yararlanılmıştır.

Bulgular: Türkçe ve İngilizce program içinde elektronik ortamı kullanan öğrencilerin komite notları diğer öğrencilerin not ortalamalarından yüksektir. Modülü kullanan öğrencilerin komite notlarındaki patoloji not ağırlığı yüksektir (Türkçe Program; $\mathrm{U}=9953.500, \mathrm{p}=.002$, $\mathrm{r}=.172$ - İngilizce Program; $\mathrm{U}=3993,500$, $\mathrm{p}=.040, \mathrm{r}=.146)$. Aynı grubun patoloji laboratuar sınav sonuçları anlamlı şekilde yüksek olduğu bulunmuştur (Türkçe Program; $\mathrm{U}=8627.000, \mathrm{p}=.000, \mathrm{r}=.261-$ İngilizce Program; $\mathrm{U}=3854,500, \mathrm{p}=.014, \mathrm{r}=.174)$. Öğrenci geribildirimlerde tasarıma ilişkin memnuniyet ifadeleri yer almıştır.

Tartışma ve Sonuç: $\mathrm{Bu}$ çalışmada eğitici, ders performansına yönelik olumlu yönde doyum ifadeleri kullanmış, yeni öğretim yaklaşımını diğer komitelerde de kullanma isteğini belirtmiştir. Sanal mikroskop ve elektronik preperat arşivi uygulamalarının laboratuvar uygulamalarını desteklemek amaçlı kullanılabileceği söylenebilir. Öğrencilerin etkileşim ve iletişim kanallarını etkin kullanmama durumlarındaki sorunları irdeleyen çalışmalara gereksinim olduğu değerlendirilmektedir.

\section{ABSTRACT:}

Background and aims: Pathology education at Hacettepe University Faculty of Medicine is carried out in the form of an amphitheater and a laboratory. Pathology teaching in medical faculties that conduct integrated programs aims to provide medical students with the competence in three main areas. These; a- Understanding of disease mechanisms. $b$ - Integration of these mechanisms to organ system pathology and capplication of pathology to diagnostic medicine. The current practice involves some problems with students' participation, using microscopes and evaluating the preparations. In this study, the effect of a teaching design, which is covered by a learning-centered approach and also using technology-supported learning environments, in the pathology teaching was evaluated.

Methods: The study was carried out in the 20172018 academic year 3rd-year Urogenital System course with 261 medical students. The design includes the following elements: a-Pathology course content is systematically structured and presented in an electronic indexed book format. $b$ - Assessment questions have been included. c- Electronic communication channels have been formed in which students can discuss and give feedback. $d$-Students have access to the electronic prepared archive and virtual microscope application. e- For data collection; multiple-choice examination, pathology laboratory examination, program evaluation, and educational reflections forms were used.

Results: The grades of the students who use the electronic environment in both groups are higher than the average scores. The pathology score of the students using the technology supported environment is high ( $U=9953.500, p=.002, r$ $=.172$; and $U=3993,500, p=.040, r=.146$ ). The pathology laboratory test results of the same group were significantly higher than the other group $(U=8627.000, p=.000, r=.261$; and $U=3854,500, p=.014, r=.174)$. The feedback from the students mentioned satisfaction with the new approach.

Discussion and Conclusions: The trainer was highly satisfied to use the new model. Multiple displays of content enhance the learning of individuals in different styles. Applications 
of virtual microscope can be used to support laboratory applications in view of the increase in image quality, the ability of everyone to see the same image and discuss the same image in common sessions.

\section{Giriş}

Tıp eğitimi, hekim adaylarının alana ait temel (temel, klinik ve sosyal bilimler) bilgileri edinmesini, vücut sistemlerinin normal ve patolojik çalışma mekanizmalarını anlamasını, sağlık sorunlarına tanı koyması ve tedavi etmesini, profesyonel değerler ve bilimsel kanıtları temel alarak mesleki uygulamalarını yapmasını ve kendisini sürekli geliştirmesini hedefler. Eğitim programında fizyopatolojik mekanizmaları anlama, ayırıcı tanı yapma, tanı ve tedavi kararı verme süreçlerinde Patoloji biliminin bilgi ve yöntemlerinden yararlanılır. $\mathrm{Bu}$ bağlamda patoloji laboratuvarının işlevi merkezi bir role sahiptir. Tip öğrencileri fizyopatolojik mekanizmalar ve klinik semptomatoloji bilgilerini hastadan elde ettikleri anamnez ve fizik muayene bulguları ile birleştirerek tanı ve tedavi süreçlerini yönetmeyi öğrenmelidir (1). Patoloji, bilişsel bağlamı görsel bakımından zengin bir disiplin olarak tanımlanır (2). Daha geniş anlamıyla patoloji, hastalıklara yol açan nedenleri, bunların doku ve organları etkileme biçimlerini, hastalıklı doku ve organların özellikle morfolojik (biçimsel, görüntüsel) özelliklerini inceler. Mezuniyet öncesi tıp eğitiminde sistem temelli entegre müfredatlar yaygınlaşırken, tıbbi patoloji biliminin müfredat içerisinde uygun şekilde temsil edilmesi ve temel patolojik mekanizmasüreçlerin öğretilmesinde entegrasyonun sağlanması kaçınılmazdır. Entegre program yürüten tıp fakültelerinde patoloji öğretimi tıp öğrencilerinin üç temel alanda yetkinlik kazanmalarını amaçlamaktadır. Bunlar; a-Hastalık mekanizmalarının anlaşılması, b- Mekanizmaların organ sistem patolojisine entegrasyonu ve c- Patolojinin tanisal tibba uygulanmasidir (3).

Geleneksel olarak, patoloji eğitim ve öğretiminde, ders kitapları, cam slaytlar ve geleneksel mikroskopi kullanılmaktadır. Eğitici deneyimine göre, özellikle diğer disiplinlerle bütünleşik, bağlamsal ve özendirici bir şekilde patolojik süreçleri öğrenmeye yardımcı olacak eğitim kaynaklarının yetersizliği nedeniyle öğrencilerin öğrenmelerinde eksiklikler gözlemlenmektedir. $\mathrm{Bu}$ öğretim tarzı hem öğrenci hem de eğitici için, başkalarının ne tartıştığını tam olarak görememe, sadece sınıfta öğrenebilme ve sınıf dışı öğrenmelerin gereksinimlerini karş1layamama gibi çeşitli problemler doğurur. Mevcut eğitim uygulamaları ögrencinin derse katılımı, mikroskop kullanma ve çoklu preparatları değerlendirebilme konusunda sorunlar içermektedir (4).

Patoloji, teknolojik gelişmelerden yararlanma ve uygulama konusunda öncü disiplinlerden biridir. Görüntüleme teknolojilerindeki gelişmeler, mikroskoptan manuel olarak incelenebilen patoloji preparatlardan yüksek çözünürlüklü görüntülerinin elde edilmesine ve elde edilen dijital görüntüyü x-y ekseninde kaydırmaya ve bir büyütmeden diğerine geçmeye izin veren bir dosya formatına dönüştürmeyi olanaklı kılmıştır (5). Sanal mikroskopi olarak da adlandırılabilecek dijital patoloji, bir cam slayttaki analog bilgilerin dijitalleştirilmesini, yönetilmesini, analiz edilmesini ve yorumlanmasını içerir. Dijital mikroskopi yazılımları ile patoloji preparat görüntüleri elektronik ortamda saklanabilmekte ve istediği anda sistemden erişilebilmektedir. Dijital patoloji uygulamaları ile doku örnekleri içeren cam slaytların sayısal hale çevrilmesinde 
bütün-slayt görüntü tarayıcıları kullanabilmekte, yüksek çözünürlüklü ve zengin renk derinliğine sahip sayısal görüntüler elde edilebilmektedir (6). Eğiticiler eğitim programında dijital patolojiyi içine alan web tabanlı zengin kaynaklar oluşturmalarını ve sunmalarını sağlayan bulut tabanlı ya da ağ temelli eğitim çözümleri kullanabilmektedir. Bu uygulamalar zengin renk derinliği ve yüksek çözünürlüklü görüntülemeden, dinamik gösterimler ve etkileşimden yararlanmakta, ortam olarak ağsal fiziksel yapıları ve bulut sistem özelliklerini kullanabilmektedir.

Patoloji eğitiminde WEB tabanlı eğitim materyali oluşturmanın bazı yararları şunlardır: Kapsamlı içerik oluşturma, yeniden kullanılabilirlik, öğrenci gelişiminin izlenmesi, değerlendirme verisi toplama yeteneği. Patoloji Web tabanlı eğitim uygulamalarının öz düzenlemeli öğrenme ve harmanlanmış öğretim ilkelerine göre tasarlanması yönünde bir eğilim söz konusudur $(7,8)$.

Karma (Harmanlanmış) öğrenme bir amaç doğrultusunda (öğretimin verimini artırmak, maliyeti düşürmek vb.) birden çok eğitim modelinin temel unsurlarının birlikte kullanılmasıdır. $\mathrm{Bu}$ modelde, genellikle e-öğrenmeye dayalı uzaktan öğrenme ile yüz yüze öğrenme etkinlikleri ve öğretim teknikleri birlikte kullanılır (9). Karma öğrenmede amaç, en uygun öğretim programını oluşturmak amacıyla farklı öğretim ortamlarını birleştirerek öğretimi daha etkin kılmaktır (10). Bilgiye erişebilirlik, pedagojik etkiler, etkileşimli ders gibi avantajlar dolayısıyla harmanlanmış öğrenmeye ilgi artmaktadır (8). Eğitim ortamlarının harmanlanmasında öğretimin hedefleri, öğrenenlerin bilgi ve beceri düzeyleri, öğreticilerin tercihleri gibi değişkenler dikkate alınarak harmanlama oranları ve şekillerinde değişikliğe gidilebilir (11).
Öz-düzenleme, öğrenenlerin zihinsel yeteneklerini akademik performans becerilerine dönüştürmelerini sağlayan öz-yönlendirici bir süreçtir. Öz-düzenlemeli öğrenmede, öğrenciler, öğrenme için gerekli etkinlikleri başlatır, öğrenme etkinliğine değer yükler, öğrenme hedefine başlamak için kendilerini motive ederler. Winne'ın “dört evreli özdüzenlemeli öğrenme modelinin evreleri aşağıdaki gibi özetlenebilir (12, 13): a. Görev tanımlama b. Hedef koyma ve planlama c. Çalışma taktiklerini ve stratejilerini yürürlüğe koyma d. Gelecekteki ihtiyaçlarını gözeterek metabilişsel çalışma tekniklerini uyarlama.

Hacettepe Üniversitesi Tip Fakültesinde patoloji eğitimi entegre - sistem temelli program içerisinde amfi dersleri ve laboratuvar uygulamaları şeklinde gerçekleşmektedir. Mevcut uygulama öğrencilerin derse katılımı, mikroskop kullanma ve preparatları değerlendirmelerinde sorunlar içermektedir. Eğiticiler, öğrenmeyi teşvik eden, anlamlı kılan ve mevcut olan teknolojik kaynakları öğrenme sürecine entegre eden yeni yöntemler arayış1 içindedir. Eğiticilerin öğrencilerin patoloji bilgi birikimini ve uygulama becerilerini geliştirme, derse aktif katılımlarını destekleme istekleri doğrultusunda öğretim tasarımı geliştirilmiştir. $\mathrm{Bu}$ çalışmada, öğrenen merkezli bir yaklaşımla ele alınan ve dijital patoloji uygulamasını da kullanan harmanlanmış bir öğretim tasarımının patoloji öğretiminde etkililiği ele alınmıştır.

\section{Yöntem}

Kapsam: Ürogenital Sistem Hastalıkları komitesi içerisinde patoloji anabilim dalının Uterus hastalıkları, Over Tümörleri ile Plasenta ve Gestasyonel Trofoblastik Hastalıklar derslerin amfi oturumu, laboratuvar uygulaması ve ele alınan konularla ilgili çevrimiçi özyönetimli öğrenme ortamından oluşmaktadır. 

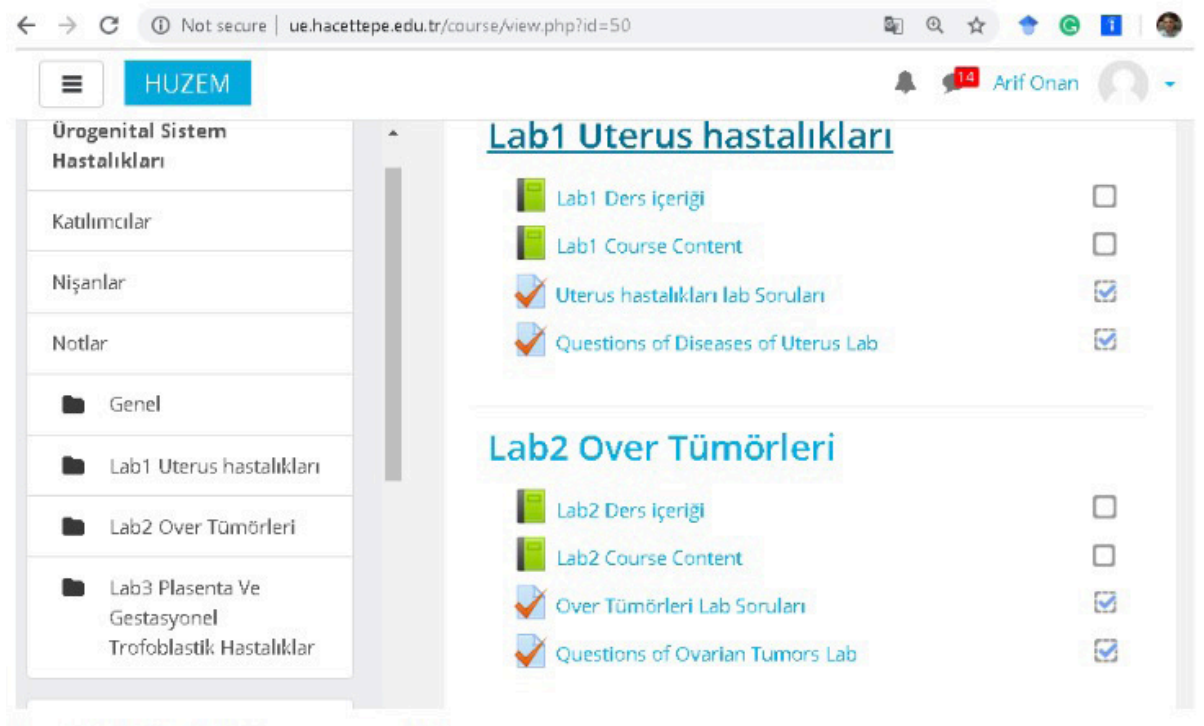

Q $Q$ \& क

\section{Resim 1. Moodle E-öğrenme modülü}

Tasarım: Çevrimiçi öğrenme ortamı kohort öğrencilerine kişisel bilgisayarlarından erişilebilir hale getirilmiştir ve cep telefonları ve tabletler gibi mobil cihazlarla uyumluluk gözetilmiştir. Ortam ve içerik Türkçe ve İngilizce program gereklerine uygun olarak tasarlanmıştır. Ders notları Moodle kitap formatında hiyerarşik olarak indexlenmiştir ve öğrencilerin hangi konuya hangi sıklıkla eriştikleri ve hangi içerikle etkileşim kurdukları hakkında veri elde edilmesi sağlanmıştır. Öğrencilerin öğrenmelerini gözden geçirmelerini kolaylaştıran bağlamsal ek açıklamalar sunan sistematik bir yapı tasarlanmıştır (Resim 1). Ders içeriğine uygun çoktan seçmeli sorular eklenerek öğrencinin öğrenme çıktılarını karşılayıp karşılamadıkları hakkında değerlendirme yapmaları olanağı sunulmuştur. Ders içeriğine uygun vaka örnekleri eklenerek öğrencilerin üst düzey düşünme becerilerini geliştirmelerine yönelik öğrenme olanakları sunulmuştur. Her bir konu içeriği öğrencilerin pratik oturumlarda ele alınan konuları incelemelerine yardımcı olacak etkileşimli bir mikroskopi bölümü içermektedir (Resim 2 ). Öğrenciler ve öğretim elemanlarının çevrimiçi araç aracıllı̆ıyla birbirleriyle tartı̧̧acăğ geribildirim verebilecekleri ve etkileşim kuracakları elektronik iletişim kanalları oluşturulmuştur. Öğrencilerin komitede ele alınan patoloji derslerini kapsayan slayt arşivinin yer aldığı VS120 Virtual Slide Microscope uygulamasına erişmeleri için gerekli düzenleme yapılmış ve kullanıcı yetkilendirmesi gerçekleştirilmiştir. $\mathrm{Bu}$ araç Hacettepe Üniversitesi fiziksel ağında yer aldığı için Moodle çevrimiçi öğrenme yönetim sisteminden VS120'e geçiş için bir bağlantı eklenmiştir (http://digitalpatoloji.hacettepe.edu. tr). 


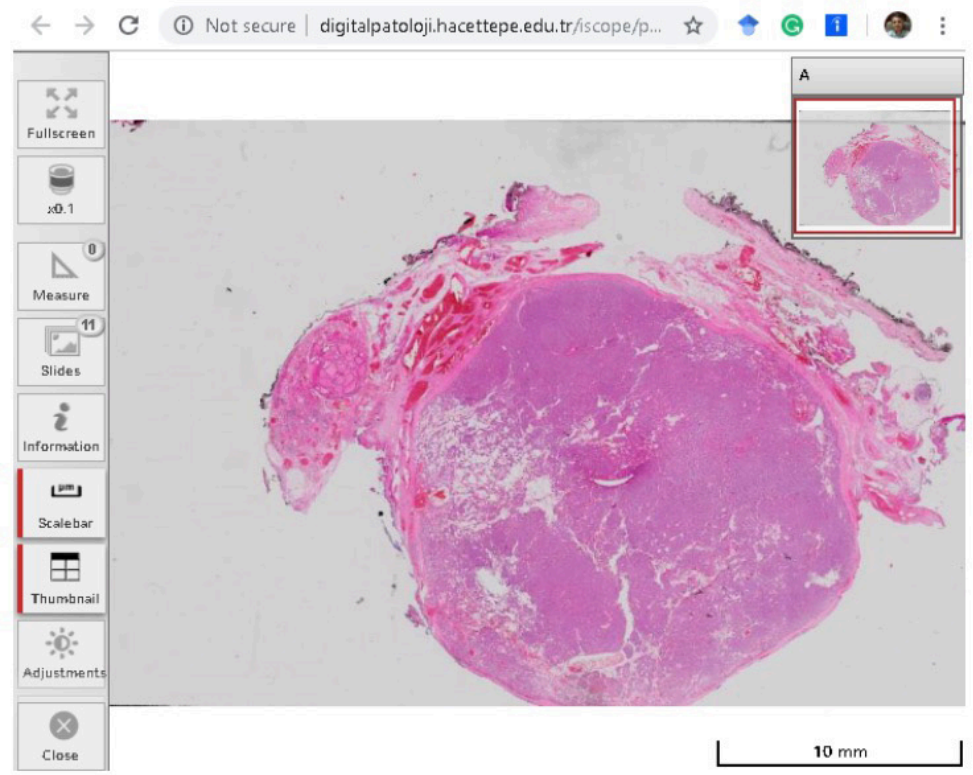

Resim 1. VS120 Sanal Slayt Mikroskop Tutor uygulaması

Uygulama: Çalışma 2017-2018 akademik y1l1 3. sınıf Ürogenital Sistem ders kurulunda gerçekleştirilmiştir. 532 öğrenciden koşulları karşılayan ve yazılı sınava giren 515 öğrenci raporlamaya dahil edilmiştir. Elektronik ortamı 261 öğrenci aktif olarak kullanmıştır.

Ölçme araçları: Öğrencilerin katıldığı zorunlu komite çoktan seçmeli sınavı (Toplam 100 çoktan seçmeli soru, 23 adedi patoloji konu alanını temsil etmektedir.), Komite içerisinde zorunlu patoloji laboratuvar sinavi (10 soru), Komite sonunda uygulanan gönüllü öğrenci modül değerlendirme formu, Uygulama sonunda alınan Eğitici refleksiyonu (Açık uçlu dört soru). İstatistik karşlaştırmalarda verinin niteliğine uygun olan Mann Whitney u testi kullanılmıştır. İstatistiksel karşılaştırmalar ve ilgili bildirimler Türkçe ve İngilizce Fakülte için ayrı ayrı yapmaya, kohort karşılaştırmalarında ise birleştirilmiş değerlendirmelerde kullanmaya özen gösterilmiştir.

\section{Bulgular}

Eğitimin başarısını ölçmek için sınav başarılarına bakıldığında, her iki grup içinde (modülden yararlanan - yararlanmayan) Elektronik ortamı kullanan öğrencilerin komite notları diğer öğrencilerin not ortalamalarından yüksektir [İngilizce grup $(\mathrm{E}+\mathrm{n}: 86$, Sira Ortalamas1 $=$ 121,33 ; E- n:112, Sira Ortalamas1 $=82,74$ ) - (Türkçe grup (E+ n:175, Sira Ortalamas1 = 185,62; E- n:142, Sira Ortalamas1 $=126,19)]$. Teknoloji destekli ortamı kullanan öğrencilerin komite notlarındaki patoloji ağırlığı yüksektir (Türkçe Program $\mathrm{U}=9953.500, \mathrm{p}=.002, \mathrm{r}=$ .172 - İngilizce Program $U=3993,500, p=$ $.040, r=.146)$. Aynı grubun patoloji laboratuvar sınav sonuçları diğer gruptan anlamlı şekilde yüksektir (Türkçe Program $U=8627.000, p=$ $.000, r=.261-$ İngilizce Program $U=3854,500$, 
$\mathrm{p}=.014, \mathrm{r}=.174)$. Öğrencilerden alınan geri bildirimlerde öğrenme ortamı ve yeni yaklaşıma yönelik memnuniyet ifadeleri yer almıştır. Etkinlikte öğrencilerin etkileşim ve iletişim kanallarını kullanılmaları (Forum, chat) sınırlı düzeyde gerçekleşmiştir.

Öğrencilerin komite sonu modül değerlendirme anket sonuçları (Tablo1 ve Tablo 2) ve eğiticinin uygulama ile ilgili refleksiyonu aşağıda yer almaktadir (Tablo 3).

Tablo 1. Öğrencilerin modül değerlendirme tanımlayıcı anket maddeleri ve yüzdelik cevapları ( $n=76)$.

1. Online derslere erişmek için aşağıdaki araçlardan hangisini sıklıkla kullandınız? Kişisel bilgisayar \%59 Mobil aygıt, (Cep/Tablet)\%37,Bilgisayar lab. \%4

2. Online derslere katılabilmek için internete erişim sorunu yaşadınız mı? Hayır \%75, Bazen \%25

3. Online derslere katılabilmek için bilgisayar, tablet, cep telefonu vb. araçlara erişim sorunu yaşadınız mı?

Hiçbir zaman \%80, Bazen, \%18, Sık sık \%2

4. Bu ders için hangi öğrenme ortamını tercih edersiniz? Karma $\% 51$, Online $\% 38$, yüz yüze $\% 11$

5. Kişisel bilgisayarınız var mı? Evet \%87, Hayır \%13

Tablo 2. Öğrenci e-modül değerlendirme likert anket maddeleri ve ortalama değerleri ( $n=76)$

\begin{tabular}{|l|l|}
\hline Online ortamda eğiticiye sorduğum sorulara yanıt almaktan memnunum. & 4,14 \\
\hline Kurs boyunca eğitici ile etkili biçimde iletişim halinde bulunmaktan memnunum. & 4,38 \\
\hline $\begin{array}{l}\text { Eğiticinin derse ilişkin çeşitli eğitsel materyallere ulaşabilmem konusunda desteğinden } \\
\text { memnunum. }\end{array}$ & 4,55 \\
\hline \begin{tabular}{l} 
Eğiticinin online öğrenme konusunda hevesli olmasından memnunum \\
\hline Online ortamda eğiticiden geribildirim alabilmekten memnunum.
\end{tabular} & 4,59 \\
\hline Ünitelerin belirli bir plan dahilinde açılmasından memnunum. & 4,37 \\
\hline Ünitelerin sunum şekillerinin tutarlı olmasından memnunum. & 4,58 \\
\hline İçeriğin sunumunda kullanılan dilin açık ve anlaşılır olmasından memnunum. & 4,49 \\
\hline
\end{tabular}


Online sistem içerisinde dolaşırken kaybolma sorunu yaşanmamasından dolayı memnunum.

Çevrimiçi sistemin kullanımının kolay olmasından memnunum.

Çevrimiçi öğrenme ortamında gereksinimlerimin karşılanmasından dolayı memnunum.

Dersle ilgili soru örnekleri verilmesinden memnunum

Tablo 3. Eğitici e-modül soruları ve özet geribildirimi

1. E-öğrenme uygulamasına neden gerek duydunuz? Eğitici Refleksiyonu (ER)-1 “Öğrencilerin eğitim materyallerine daha kolay erişmesi ve ders öncesi ulaşarak konuya hakim olmasını sağlamak ve daha fazla bilgi birikimi oluşturarak, interaktif tartışma ile öğrenme düzeyini arttırmak."

2. Uygulama çıktıları beklentinizi ne ölçüde karşıladı (olumlu yönler)? ER-2 “Özellikle digital görüntülerin anfi ortamında tartışma için kullanılması öğrencilerin öğrenme düzeylerini ve memnuniyetlerini çok arttırdı. Ders, laboratuvar içeriğinin ve konu ile ilgili soruların elektronik ortamda olması sadece onlara ulaşan öğrencilere olumlu yönde katkı sağladı. Özellikle yöntemi tüm basamaklara uyarak izleyenlerde öğrenme ve memnuniyet düzeyinin daha yüksek olduğunu gözlemledim."

3. Geliştirilmesini düşündüğünüz yönler (olumsuz yönler)?

ER-3 “Öğrencilerin bu yöntemi tanımıyor oluşları, sistem hakkında bilgi sahibi olmamaları ve nasıl kullanabileceklerini bilmemeleri en büyük sorunu oluşturuyor kanımca. Ayrıca orta eğitim sisteminin interaktif tartışmaya çok açık olmaması nedeniyle öğrencilerin alışkanlıkları da etkileyen diğer bir faktör. Diğer bir nokta da öğrencilerin yeterli zamanlarının olmaması ve ders kurulu içerisinde bu eğitim saatlerinin yeri. Sınava çok yakın zamanlarda ilgi büyük oranda düşüyor."

4. Bu uygulamayı sürdürmeyi ve yaygınlaştırmayı düşünür müsünüz?

ER-4 "Bu uygulamayı yaygınlaştırmaya başladık bile. Bölüm olarak bu sistemi tüm dönem 3 laboratuvar uygulamaları için önümüzdeki sene gerçekleştireceğiz." 


\section{Sonuç ve tartışma}

Elektronik ortam kullanan öğrencilerin (Türkçe veİngilizce grupayrıayrıya dabirlikte)ekçalışma yaptıkları düşünüldüğünde komite çoktan seçmeli ve laboratuvar sınavından daha yüksek not almaları beklenen bir durumdur. Eğitimin etkililiğini göstermede öğrencilerin komite notu içerisindeki patoloji notu yüzdesindeki değişimi kullanmanın, daha yansız bir yöntem olacağ1 değerlendirilmiştir. $\mathrm{Bu}$ nedenle, öğrencilerin komitedeki patoloji yüzdelerinde gözlenen pozitif farklılık e-öğrenme modülünü kullanmaları ile ilişkilendirilmiş, patoloji konu alanında diğer gruba göre daha başarılı oldukları değerlendirilmesinde bulunulmuştur. Aynı şekilde, patoloji laboratuvar sınav sonuçları e-öğrenme modülünü kullanan öğrenciler lehine sonuçlanmıştır. Eğiticiden elde edilen geribildirim de bu sonucu destekler niteliktedir. Eğitici amfi oturumunda ve laboratuar etkinliğinde dijital mikroskopi kullanan öğrencilerden ayrıntılı sorular geldiğini, onlara nitelikli açıklama yapma firsatı bulduğunu ve uygulamanın öğrencilerin derse katılımını geliştirdiğini gözlemiştir. Ders içeriğinin elektronik ortamda sunulmasının öğrencinin yüzyüze etkinliklere katılımını azaltıp azaltmadığı alanyazında tartışmalı bir konudur. Sağol ve arkadaşları (2015) da öğrencilerin slaytlara elektronik ortamda ulaşmalarının öğrencilerin pratik uygulamalara katılımını düşürmediğini bildirmişlerdir.

Eğiticinin motivasyonunda öğrenci memnuniyeti önemli bir unsurdur. Bu çalışmada eğitici programa yönelik refleksiyonunda kendi performansına yönelik olumlu yönde doyum ifadeleri kullanmış, yeni öğretim yaklaşımını bölüm olarak diğer komitelerde de kullanmayı planladıklarını belirtmiştir (Tablo 3). Öğrenciler harmanlanmış öğrenme uygulaması için olumlu bildirimlerde bulunmuşlardır. Dersi tekrar
(Öğrenci Geribildirimi 1 (ÖG-1), erişebilirliği ve karma yöntemi yararlı bulma (ÖG-2), öğrenmeyi destekleme ve geliştirme (ÖG3) konu başlıklarında olumlu geribildirimler alınmıştır. ÖG-1 "Lab sınavından önce tekrar amaçlı kullanacağım”, ÖG-2 "Sistem henüz yeni olduğu için. Yoksa oldukça yararlı bir sistem her şeyin bir bütün halinde ulaşılabilir ve net olması çok güzel. Derslerin yüz yüze olmasından çok fayda gördüm. Daha önce anlamadıklarımı, preparatta nereye bakmalıyım anladım" ÖG-3 "Lab derslerine katıldım, şimdiye kadar ki en faydalı patoloji lablarını işledim. Diğger komitelerde de bu şekilde devam etmesini dilerim."

Öğrencilerin e-öğrenme modülünü kullanmalarını özendirme konusunda sıkıntılar olduğu gözlenmiştir. Elektronik ortamı 261 öğrenci aktif olarak kullanırken 254 öğrenci hiç erişim gerçekleştirmemiştir. Öğrencilerin komite bloklarının e-modül ile desteklendiği uygulamalarla daha önceden karşılaşmamış olmalarının öğrenci katılımı üzerinde etkili olduğu düşünülmektedir (ÖG-4). ÖG-4 “İlk kez böyle bir sistem denendiği için benim de bu sistemi kullanabilme sistematiğimi oturtmam biraz zaman ald1. İlk lab dersine mesela okumadan girdim, sonra ikincisinde hazırlayarak girdim çünkü az çok sistemin nasıl devam edeceğini anladım”. Öğrenci ve eğitici geribildirimleri birbirini destekler niteliktedir. Eğitici öğrencinin hazırlanan modülün sistematiğini anladığında ve basamaklara uygun şekilde çalıştıklarında daha başarılı olduklarını ifade etmektedir.

Bir başka sorun alanı ise etkileşim ve iletişim kanallarının e-modülü kullanan öğrenciler tarafindan yeterince kullanılmamasıdır. Öğrencilerin soru yöneltecekleri ve tartışacakları kanallar sunulmasına rağmen forum tarzı iletişim kanallarını kullanmayı 
tercih etmedikleri görülmüştür. Öğrencilere bu kanalları kullanmama nedenleri sorulmuş ve ögrrenciler amfi ortamında ve laboratuvar ortamında yüzyüze soru yöneltme ve yanıt alma şanslarının olduğunu ve elektronik ortama gerek duymadıklarını bildirmiştir (ÖG-5,6). ÖG-5 "Bu komite için amfi derslerinin de olması nedeniyle sorularımı orada sormayı tercih ettim." ÖG-6"Aklima takilan sorular olsaydi kullanacaktim”. Bir başka neden olarak kullanımı bilmeme, farkında olmama, uyum sağlayamama gibi bildirimler yapılmıştır (ÖG-7). ÖG-7 “nasıl kullanılacağını henüz bilmediğim için" "o özelliklerin açık olduğunu bilmiyordum." "Uyum sağlayamadım sanırım. Sonraki sefer olursa, kullanmaya çalışacağım.” Alanyazında öğrencinin iletişim kanalı kullanmaları tercihi üzerinde kuşak özelliklerinin ya da kohort karakteristiklerinin etkili olduğu yönünde bildirimler mevcuttur. Moodle benzeri öğretim yönetim sistemlerinin sunduğu genel iletişim araçların (Forum, chat) öğrencilerin alışık olduğu whatsapp, facebook gibi uygulamalara benzerlik göstermemesi öğrencilerin tercihini etkileme potansiyeline sahiptir $(14,15)$. $\mathrm{Bu}$ çalışma böyle bir karşılaştırmayı yapacak şekilde desenlenmemiştir. Öğrencilerin etkileşim ve iletişim kanallarını kullanmalarındaki sorunları irdeleyen ve bu kanalların etkili kullanımına odaklanan ileri çalışmalara gereksinim olduğu değerlendirilmektedir.

İçeriğin çoklu gösterimi farklı öğrenen bireylerin öğrenmelerini geliştirmektedir (ÖG-8). ÖG-8 "Derste çok fazla kişinin bulunması nedeniyle yeterince interaktif bir ders zaten işlenemiyor. $\mathrm{Bu}$ yöntemle hem daha aktif, hem de daha kolay şekilde bilgiye erişebiliyorum." Yüksek laboratuar puanı alan grup dikkate alındığında, dijital mikroskop uygulaması ve preperat arşivi uygulamalarının laboratuvar

uygulamalarını

desteklemek amaçlı kullanılabileceği söylenebilir. Sağol ve arkadaşları (2015) öğrencilerin slaytları işbirliği içinde izlemekten hoşlandıklarını ve bu durumun öğrencilerin histopatoloji anlayışını geliştirdiğini bildirmektedir.

Patoloji e-öğrenme modülü ile öğrencilerin özdüzenlemeli öğrenme ortamına katılmaları için olanak yaratmaktadır. Öğrenme hedeflerinin önden paylaşılması ile öğrencileri hedef seçmeye ve değerlendirme soruları vererek ölçüt belirlemeye yönlendirmektedir. Amfi ortamına hazırlıklı gelen öğrencinin yansıtıcı özdeğerlendirme yapmalarına olanak sağlanmıştır. E-öğrenme modülünde nitel ve niceliksel, yüzyüze ortamda ise niteliksel geribildirim verebilmektedir. Öğrenciler özdüzenleme becerilerini geliştirdiklerini, metabilişsel stratejilerini uyarlama yoluna gittiklerini bildirmişlerdir (ÖG-1, 4, 7).

Bildirimde bulunan öğrencilerin büyük çoğunluğu kişisel bilgisayar sahibidir (\%87) (Tablo 1). Ancak e-modülü kullanmada kişisel bilgisayarları olmasına rağmen taşınabilir aygıtlarını da kullandıkları (\%37) belirtmişlerdir (Tablo 1). Bu tercih durumu öğrenme ortamının düzenlenmesinde taşınabilir aygıt uyumluluğuna önem verilmesi gerektiğini ortaya koymaktadır. Öğrencilerin \%20 si online derslere katılabilmek için bilgisayar, tablet, cep telefonu vb. araçlara erişim sorunu yaşadığını bildirmektedir (Tablo 1). Bu sorunun giderilmesinde genel kullanıma açık aygıtlara erişimimin geliştirilmesi yararlı olacaktır. Öğrencilerin internet erişimi ile ilgili yakınmaları \%25 oranındadır (Tablo 1). $\mathrm{Bu}$ sorunun ne kadarının kampüs kaynaklı olduğuna dair elimizde kanıt bulunmamaktadır. Öğrencilere kampüs içi ya da dışında internet erişimini kolaylaştırıcı yaklaşımların desteklenmesi yararlı olacaktır.

Uygulanan etkinliğin sonuçları bir arada 
değerlendirildiğinde, (ortaya konan sorunları gözard1 etmeksizin) patoloji eğitiminde harmanlanmış öğretim tasarımının genel olarak öğrenci başarısında ve memnuniyetinde artışa yolaçtı̆̆ 1 , eğiticinin uygulamadan hoşnut kaldığ1 ve geliştirerek sürdürmek istediği görülmektedir. Aksayan yönlerin nedenlerinin ortaya çıkarılması için daha derinlemesine araştırma yapmak uygun olacaktır.

Bu çalışmanın sınırlı bir kısmı ve ön bulguların özeti Ulusal Tip Eğitimi Kongresi 2018, İzmir' de sözel bildiri olarak sunulmuştur. Yazarlar tarafindan çıkar çatışması bildirimi bulunmamaktadir.

\section{KAYNAKLAR}

01. Knollmann-Ritschel, B. E., Regula, D. P., Borowitz, M. J., Conran, R., \& Prystowsky, M. B. (2017). Pathology competencies for medical education and educational cases. Academic pathology, 4, 2374289517715040.

2. Maley, M. A., Harvey, J. R., Boer, W. B. D., Scott, N. W., \& Arena, G. E. (2008). Addressing current problems in teaching pathology to medical students: blended learning. Medical teacher, 30(1), e1-e9.

3. Sadofsky, M., Knollmann-Ritschel, B., Conran, R. M., \& Prystowsky, M. B. (2014). National standards in pathology education: developing competencies for integrated medical school curricula. Archives of Pathology and Laboratory Medicine, 138(3), 328-332.

4. Sağol, Ö., Yörükoğlu, K., Lebe, B., Durak, M. G., UlukuŞ, Ç., Tuna, B., ... \& Özer, E. (2015). Transition to Virtual Microscopy in Medical Undergraduate Pathology Education: First Experience of Turkey in Dokuz Eylül University
Hospital. Turkish Journal of Pathology, 31(3), 175-180

5. Hamilton, P. W., Wang, Y., \& McCullough, S. J. (2012). Virtual microscopy and digital pathology in training and education. Apmis, 120(4), 305-315.

6. Dee, F. R., \& Meyerholz, D. K. (2007). Teaching medical pathology in the twentyfirst century: virtual microscopy applications. Journal of veterinary medical education, 34(4), 431-436.

7. Carneiro, R., Lefrere, P., Steffens, K., \& Underwood, J. (Eds.). (2012). Self-regulated learning in technology enhanced learning environments (Vol. 5). Springer Science \& Business Media.

8. Fermozelli, J. A., Cesaretti, M. L. R., \& Barbo, M. L. P. (2017). Blended learning strategies in teaching general pathology at a medical course. Jornal Brasileiro de Patologia e Medicina Laboratorial, 53(3), 202-209.

9. Horzum, M. B. (2011). Transaksiyonel uzaklık algısı ölçeğinin geliştirilmesi ve karma öğrenme öğrencilerinin transaksiyonel uzaklık algılarının çeşitli değişkenler açısından incelenmesi. Kuram ve Uygulamada Eğitim Bilimleri Dergisi, 11(3), 1571-1587.

10. Ariana, A., Amin, M., Pakneshan, S., DolanEvans, E., \& Lam, A. K. (2016). Integration of traditional and E-learning methods to improve learning outcomes for dental students in histopathology. Journal of dental education, 80(9), 1140-1148. 
11. Balaman, F., \& Tüysüz, C. (2011).

Harmanlanmış öğrenme modelinin 7. sınıf öğrencilerinin fen ve teknoloji dersindeki başarılarına, tutumlarına ve motivasyonlarına etkisinin incelenmesi. Batı Anadolu Eğitim Bilimleri Dergisi, 2(4), 75-90.

12. Butler, D. L., \& Winne, P. H. (1995). Feedback and self-regulated learning: A theoretical synthesis. Review of educational research, 65(3), 245-281.

13. Winne, P. H., \& Hadwin, A. F. (1998). Studying as self-regulated learning. In D. J. Hacker, J. Dunlosky, \& A. C. Graesser (Eds.), The educational psychology series. Metacognition in educational theory and practice (pp. 277-304). Mahwah, NJ, US: Lawrence Erlbaum Associates Publishers.

14. Camus, M., Hurt, N. E., Larson, L. R., \& Prevost, L. (2016). Facebook as an online teaching tool: Effects on student participation, learning, and overall course performance. College Teaching, 64(2), 84-94.

15. Wang, Q., Woo, H. L., Quek, C. L., Yang, Y., \& Liu, M. (2012). Using the Facebook group as a learning management system: An exploratory study. British Journal of Educational Technology, 43(3), 428-438. 